\title{
Safety issues in semen banks during the COVID-19 pandemic: data from a European survey
}

\author{
S. Marchiani ${ }^{1,2}$ (1) - S. Dabizzi ${ }^{1}$ - S. Degl'Innocenti ${ }^{1}$ - M. G. Fino ${ }^{1}$ - M. G. Torcia ${ }^{1,3} \cdot$ D. Paoli ${ }^{4} \cdot$ F. Lombardo ${ }^{4} \cdot$ N. Ciccone $^{5}$. \\ S. Pollini ${ }^{3,5} \cdot$ G. M. Rossolini ${ }^{3,5} \cdot$ L. Vignozzi ${ }^{1,2} \cdot$ C. Krausz ${ }^{1,2} \cdot$ E. Baldi $^{1,3}$
}

Received: 28 October 2021 / Accepted: 16 December 2021 / Published online: 25 January 2022

(C) Italian Society of Endocrinology (SIE) 2021

\begin{abstract}
Purpose We performed a survey among European semen banks enquiring safety protocols during the COVID-19 pandemic. We report the experience from a center searching SARS-CoV-2 mRNA in semen of patients undergoing cryopreservation from May 2020 to January 2021.

Methods A questionnaire was submitted to accredited semen banks of the European Academy of Andrology (EAA) and the Italian Society of Andrology and Sexual Medicine (SIAMS). A total of 22 centers answered to the survey. SARS-CoV-2 mRNA in semen was evaluated by RT-PCR in 111 subjects banking in the Semen Bank of Careggi University Hospital (Florence, Italy).

Results No particularly drastic safety measures were adopted by the majority of the centers to prevent the risk of contamination or transmission of the virus. The most common strategy (77.3\%) was the administration of an anamnestic questionnaire. About half of the centers request a negative nasopharyngeal swab (NPS) before cryopreservation. Few centers use a quarantine tank, in case of late response of NPS, and only 4 store in a dedicated tank in case of infection. SARS-CoV-2 mRNA was not found in 111 semen samples cryopreserved in the Florentine bank.

Conclusions European semen banks use different measures to handle semen samples for cryopreservation during COVID-19 pandemic. The request of NPS is advised to better manage couples undergoing ART and to protect the personnel operating in the bank/ART center. Finally, due to the areas of uncertainties of an almost unknown virus, it is absolutely recommended the use of safe devices for sample handling and storage.
\end{abstract}

Keywords SARS-CoV-2 $\cdot$ Semen bank $\cdot$ Safety $\cdot$ Survey $\cdot$ Sexual transmission

S. Marchiani

sara.marchiani@unifi.it

1 Andrology, Women's Endocrinology and Gender Incongruence Unit, Careggi University Hospital, 50139 Florence, Italy

2 Department of Experimental and Clinical Biomedical Sciences "Mario Serio", University of Florence, 50134 Florence, Italy

3 Department of Experimental and Clinical Medicine, University of Florence, 50134 Florence, Italy

4 Laboratory of Seminology-"Loredana Gandini" Sperm Bank, Department of Experimental Medicine, "Sapienza" University of Rome, Viale del Policlinico 155, 00161 Rome, Italy

5 Clinical Microbiology and Virology Unit, Careggi University Hospital, 50139 Florence, Italy

\section{Introduction}

From December 2019, a form of pneumonia caused by a virus belonging to the Coronavirus family developed in China and it soon spread all over the world [1]. The World Health Organization (WHO) named such virus SARS-CoV-2 (Severe Acute Respiratory Syndrome Corona-Virus-2) and the relative infection COVID-19 (Corona Virus Disease 19) and, in March 2020, declared it pandemic. Since its onset, the disease has affected millions of people with a variable course, from no or few symptoms to death.

Although the main route of transmission is respiratory droplets, there is evidence of the presence of SARS-CoV-2 RNA in various biological matrices such as stool, blood and urine samples [2]. This suggests that other routes of infection are theoretically possible. 
Additionally, evidence of gender differences in COVID19 severity have been reported indicating that men are more vulnerable and have a higher risk of infection as well as more severe symptoms than women [3]. It has been hypothesized that the male reproductive system is a potential target of SARS-CoV-2 infection, as the ACE2 receptor, responsible for the virus entry into the host cells, is present in spermatogonia, Sertoli and Leydig cells of the testis, besides its high expression in the lung [4]. Recently, expression of other Coronavirus receptors was demonstrated in spermatogonia stem cell and in prostate gland [5].

Considering that several other viruses could impair testicular function and, most importantly, some of them can be found in semen [6] (for instance hepatitis viruses B and $\mathrm{C}$ (HBV and HCV) and the human immunodeficiency virus (HIV)) the possibility that also SARS-CoV-2 can be present in semen cannot be denied "a priori". We recently assess the association between gonadal function and SARS$\mathrm{CoV}-2$ clinical outcomes in a cohort of patients admitted in the respiratory intensive care unit, and demonstrated that lower baseline levels of total testosterone and calculated free testosterone levels predicted poor prognosis and mortality while being associated to the onset of hypogonadism with primary testicular impairment [7].

To date, there are no reliable data regarding seminal contamination and transmission of SARS-CoV-2 virus. The large majority of the studies did not report the presence of viral RNA in semen of patients recovered or recovering from COVID-19 [8-14]. However, in few cases of men infected or recovering from SARS-CoV-2, the virus genome was detected in seminal fluid [15-17]. Although according to a recent systematic review [18], the presence of the virus in semen is a rare event, the potential risk of sexual transmission and semen contamination of SARS-CoV-2 remains an open question. Therefore, the risk of handling and managing male gametes during COVID-19 pandemic for cryopreservation and use in Assisted Reproduction Technology (ART) should be considered. Indeed, the use of gametes of subjects positive for SARS-CoV-2 could represent a critical point for the safety and the possible reproductive consequences for couples and personnel involved in ART procedures [19].

Currently, there are no global guidelines for the management of male and female gametes and embryos during ART programs or cryopreservation procedures. However, the American Society for Reproductive Medicine (ASRM), the Society for Assisted Reproductive Technology (SART) and the European Society of Human Reproduction and Embryology (ESHRE) recommended caution to couples planning natural pregnancy or ART [20]. In 2005, the European Union issued mandatory guidelines for the screening of HBV, HCV and HIV viruses in all the patients before undergoing ART or cryopreservation. These viruses (and others) remain viable at temperatures as low as those of liquid nitrogen storage, and the fact that also SARS-CoV-2 could have the same behavior cannot be excluded. Therefore, biobanks dealing with cryopreservation and handling biological samples should apply careful and preventive measures to control and contain also the SARS-CoV-2 infection. However, at present, there is considerable confusion on which precautions to take.

We report here, the results of a survey administered to European semen banks belonging to andrology centers accredited by the European Academy of Andrology (EAA) and by the Italian Society of Andrology and Sexual Medicine (SIAMS) aimed at collecting data on precautions and safety procedures undertaken during the pandemic to minimize the risk of possible semen contamination by SARS-CoV-2.

In addition, we report the experience of Regional Reference Center-Seminal Fluid Cryopreservation-Andrology Laboratory of the Careggi University Hospital of Florence in the period from May 2020 to January 2021, which among all the others was the only one searching SARS-CoV-2 mRNA in semen samples.

\section{Materials and methods}

\section{Setting and study participants}

To have the widest possible spectrum of participation, we asked European Academy of Andrology (EAA) and the Semen Cryopreservation Committee of Italian Society of Andrology and Sexual Medicine (SIAMS) to send a survey to the accredited centers of their societies including semen banks. The survey focused on the measures adopted during pandemic period for patients undergoing semen cryopreservation. The questionnaire (Table 1) was mailed to the Directors of $n=22$ (13 European and 9 Italian) centers and included questions with fixed response options (YES or $\mathrm{NO}$ ), plus some clarifications in case of affirmative answers.

\section{Experience of the Regional Reference Center- Seminal Fluid Cryopreservation-Andrology Laboratory of the Careggi University Hospital of Florence}

According to the protocol established by the Careggi University Hospital Risk Management Unit, during the pandemic period, patients undergoing semen cryopreservation must exhibit the results of a nasopharyngeal swab (NPS) for SARS-CoV-2 (performed no longer than $72 \mathrm{~h}$ prior to semen collection) and must give the consent to use an aliquot of semen sample to search SARS-CoV-2 RNA by RT-PCR. 
Table 1 Questions included in the survey administered to Italian and European semen banks aimed to understand precautions taken during the COVID-19 pandemic to prevent possible semen contamination by SARS-CoV-2

Name of the semen cryopreservation center

Country

Questions

1. In your center, do you administer an anamnestic questionnaire regarding risk of exposition to SARS-CoV-2, previous fever and other $\square$ Yes symptoms related to COVID-19, to patients undergoing semen cryopreservation?

2. In your center, do you request a NPS to patients before semen cryopreservation? If YES, indicate the validity (i.e., 24, 48, 72 h) $\quad \square$ Yes

3. In your center, do you request the search of SARS-CoV-2 RNA in semen samples before cryopreservation? $\quad \square$ Yes

4. In your center, do you use a separate liquid nitrogen tank during pandemic period?

$\square$ No
$\square$ Yes

5. In your center, do you use a separate liquid nitrogen tank for NPS positive patients? $\square$ Yes (in case of answer YES to question 2) $\quad \square$ No

6. In your center, do you use a quarantine liquid nitrogen tank to wait for the report of the NPS? (in case of late report) $\square$ Yes

$\begin{array}{r}\square \text { No } \\ \hline\end{array}$

\section{Semen collection}

Semen samples were obtained by masturbation and collected in sterile containers. After liquefaction of the sample and measurement of the volume, an aliquot of the sample $(230 \mu \mathrm{L})$ was used for the evaluation of the presence of the SARS-CoV-2 virus by RT-PCR and the remained semen volume was used for semen analysis and subsequent cryopreservation according to routine procedure.

\section{Detection of SARS-CoV-2 in semen samples}

All the samples were processed on the same day of collection at the center of Microbiology and Virology Unit of the Careggi University Hospital of Florence. Detection of SARS-CoV-2 was performed according to the method previously published [17]. Briefly, sample nucleic acids were extracted with the Microlab Nimbus IVD system (Seegene Inc, Seoul, South Korea) using the Starmag Universal Cartridge kit and amplified with the multiplex RT-PCR Allplex TM SARS-CoV-2 assay (Seegene Inc), taking as target genes RdrP, E and N, according to the manufacturer's instructions. The amplification reaction was carried out for a total of 45 cycles and the presence of specific amplification products of the target genes was evaluated using the $\mathrm{Ct}$ value through Seegene Viewer analysis software. An exogenous gene target was included prior to nucleic acids extraction to each sample, as required by the manufacturer, and used as internal control to monitor the process of nucleic acid extraction and to exclude the presence of any possible RT-PCR inhibitors.

\section{Data management and analysis}

Data of each center were recorded in a database and different percentages related to each answer were calculated. In addition, data regarding the search of SARS-CoV-2 mRNA in semen of subjects undergoing cryopreservation at the Regional Reference Center-Seminal Fluid Cryopreservation-Andrology Laboratory of the Careggi University Hospital of Florence were recorded in a database and the relative percentages calculated.

\section{Results}

\section{Answers to survey}

All contacted centers performing semen cryopreservation returned completed survey. Types of institutes were 1 private clinic, 17 university hospitals, 4 public hospitals (for details see Table 2).

Among the Italian centers (Fig. 1A), 6/9 (66.7\%) administer an anamnestic questionnaire on COVID-19 to patients, $3 / 9(33.3 \%)$ ask for NPS before semen cryopreservation within the $72 \mathrm{~h}$ before the procedure. Only the center of Careggi University Hospital (11.1\%) performed the search for viral RNA in semen before storing the sample. 3/9 (33.3\%) centers store the sample in a quarantine tank in the absence of NPS response and, only two centers, adopt a dedicated tank in case of SARS-CoV-2 positive subjects (22.2\%).

Among European centers (Fig. 1B), 11/13 (84.6\%) screen patients by administering an anamnestic questionnaire on COVID-19, 7/13 (53.8\%) asked NPS results before semen cryopreservation ( 2 of them within $72 \mathrm{~h}, 2$ within $48 \mathrm{~h}$ and 1 within $24 \mathrm{~h}$ before the cryopreservation procedure; 2 centers did not indicate the timing of NPS respect to cryopreservation procedure). No center performs the search of viral mRNA in semen before storing the sample. Regarding the use of separate tanks, only 4/13 (30.8\%) centers store the sample in a quarantine tank in case of urgent 
Table 2 List of centers participating to the survey

\begin{tabular}{|c|c|c|c|}
\hline Participating center & Country & Director & Scientific society \\
\hline Brussels, Center for Reproductive Medicine & Belgium & Prof. Herman Tournaye & EAA \\
\hline Copenhagen, Dept of Growth and Reproduction & Denmark & Dr. Niels Jørgensen & EAA \\
\hline $\begin{array}{l}\text { Florence, Regional Reference Center-Seminal Fluid Cryopreserva- } \\
\text { tion-Andrology Laboratory of the Careggi University Hospital of } \\
\text { Florence }\end{array}$ & Italy & Prof. Linda Vignozzi & EAA, SIAMS \\
\hline $\begin{array}{l}\text { Ghent, Dept's of Endocrinology, Reproductive Medicine and Urol- } \\
\text { ogy }\end{array}$ & Belgium & Dr. Guy T'Sjoen & EAA \\
\hline Halle-Saale, Center for Reproductive Medicine and Andrology & Germany & Prof. Hermann M. Behre & EAA \\
\hline $\begin{array}{l}\text { L'Aquila, Andrology Unit, Department of Life, Health and Environ- } \\
\text { mental Sciences, University of L'Aquila }\end{array}$ & Italy & Prof. Felice Francavilla & SIAMS \\
\hline $\begin{array}{l}\text { Latina, Andrology and Pathophysiology of Reproduction Unit, Santa } \\
\text { Maria Goretti Hospital }\end{array}$ & Italy & Dr. Pietro Salacone & SIAMS \\
\hline Leuven, Dept of Endocrinology/Andrology & Belgium & Prof. Dirk Vanderschueren & EAA \\
\hline Malmo, Reproductive Medicine Center & Sweden & Prof. Aleksander Giwercman & EAA \\
\hline $\begin{array}{l}\text { Milan, Assisted Reproduction Techniques Unit, Ospedale Santi } \\
\text { Paolo e Carlo }\end{array}$ & Italy & Dr. Patrizia Sulpizio & SIAMS \\
\hline $\begin{array}{l}\text { Milan, Infertility Unit, Fondazione IRCCS Ca' Granda Ospedale } \\
\text { Maggiore Policlinico }\end{array}$ & Italy & Prof. Edgardo Somigliana & SIAMS \\
\hline $\begin{array}{l}\text { Moscow, N. A. Lopatkin Scientific Research Institute of Urology } \\
\text { and Interventional Radiology }\end{array}$ & Russia & Prof. Oleg Apolikhin & EAA \\
\hline Münster, Center of Reproductive Medicine and Andrology & Germany & Prof. Sabine Kliesch & EAA \\
\hline $\begin{array}{l}\text { Padua, Regional Reference Center-Seminal Fluid Cryopreserva- } \\
\text { tion-Andrology and Reproductive Medicine }\end{array}$ & Italy & Prof. Carlo Foresta & SIAMS \\
\hline Riga, Clinic IVF-Riga & Latvia & Dr. Juris Erenpreiss & EAA \\
\hline $\begin{array}{l}\text { Rome, Laboratory of Seminology-Sperm Bank "Loredana Gandini”, } \\
\text { Department of Experimental Medicine, "Sapienza” University of } \\
\text { Rome }\end{array}$ & Italy & Prof. Francesco Lombardo & EAA, SIAMS \\
\hline Rotterdam, Erasmus Medical Centre & Netherlands & Dr. Gert Dohle & EAA \\
\hline $\begin{array}{l}\text { Siena, Centre for Diagnosis and Treatment of Couple Sterility, Siena } \\
\text { University Hospital }\end{array}$ & Italy & Prof. Vincenzo De Leo & SIAMS \\
\hline $\begin{array}{l}\text { Stockholm, ANOVA-Karolinska University Hospital and Karolin- } \\
\text { ska Institutet }\end{array}$ & Sweden & Prof. Mats Holmberg and Lars Björndahl & EAA \\
\hline Thessaloniki, Aristotle University of Thessaloniki & Greece & Prof. Dimitrios Goulis & EAA \\
\hline $\begin{array}{l}\text { Turin, Unit of Andrology, Seminology and Cryopreservation, G.I.D.; } \\
\text { Department of Medical Sciences, University of Turin }\end{array}$ & Italy & Dr. Giovanna Motta & SIAMS \\
\hline Zagreb, School of Medicine, University of Zagreb & Croatia & Prof. Davor Jezek & EAA \\
\hline
\end{tabular}

Name, country, director and scientific society of each center are reported

cryopreservation and in the absence of NPS response. Moreover, in case of positive NPS, only $2 / 13$ (15.4\%) centers employ a separate tank and only one center uses a separate tank for all semen samples stored during the pandemic period.

All centers accepted to cryopreserve semen samples of patients with a positive NPS (hospitalized or not) when the cryopreservation cannot be delayed for health problems (i.e., oncological patients with the urgency to start the therapies).

Noteworthy, also within European centers of the same country, different protocols are used. In particular, of the two Belgian centers only one requests NPS before cryopreservation; of the two German centers, only one foresees both NPS before cryopreservation and the use of a quarantine tank and, finally, only one of the two Swedish centers administers the anamnestic questionnaire, while the other does not foresee any particular procedure.

The answers of all centers (Italian and European) together are reported in Fig. 1C. 


\section{A}

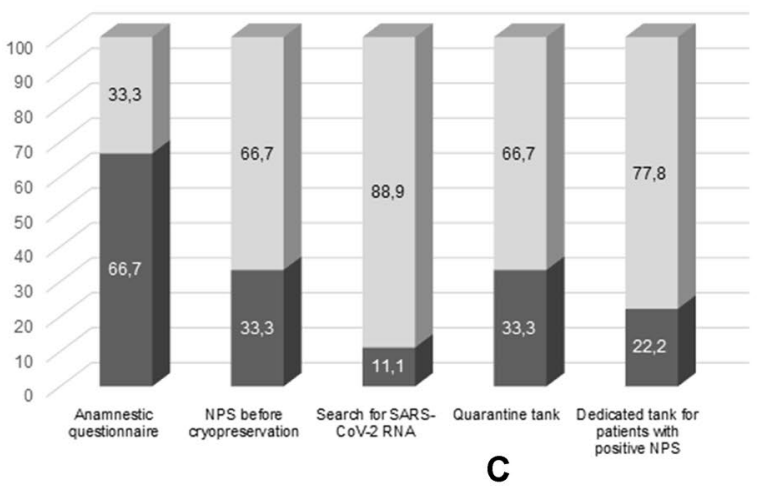

B

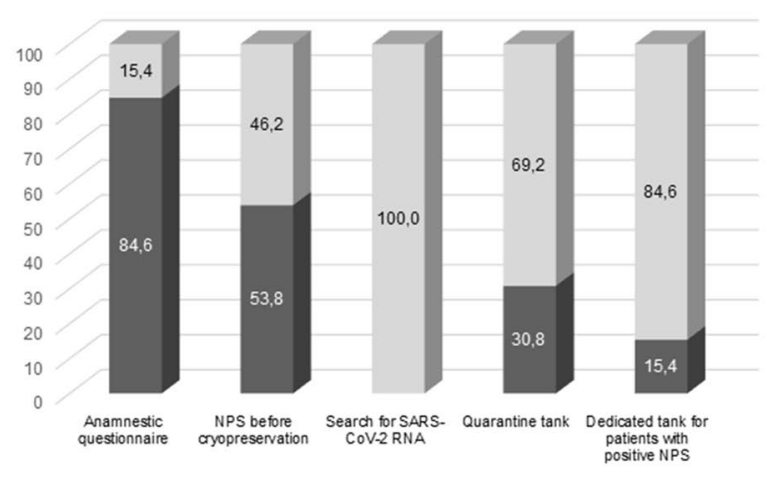

All centers

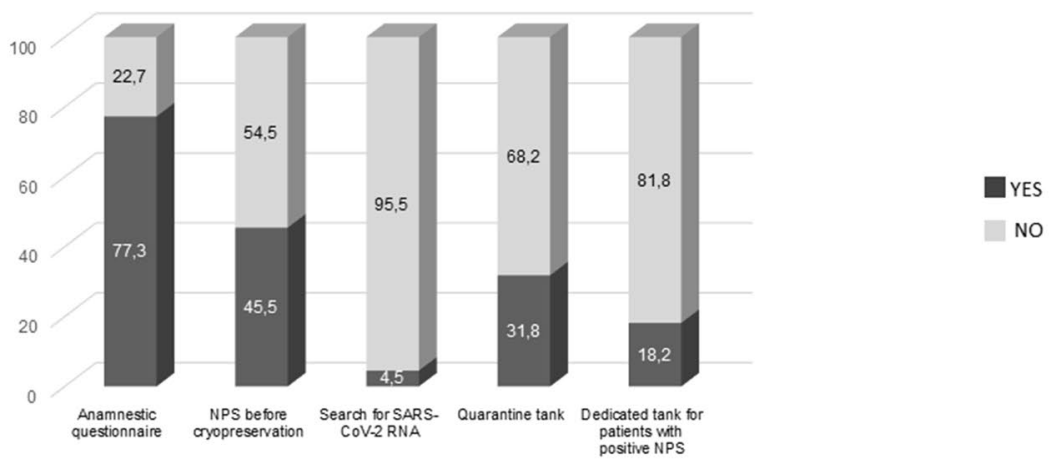

Fig. 1 Stacked bar chart representing the percentages of Italian (panel $\mathbf{A}, n=9$ ), European (panel $\mathbf{B}, n=13$ ) and all (panel $\mathbf{C}, n=22$ ) centers answered Yes or No to questions of survey

\section{Detection of SARS-CoV-2 in semen samples from subjects who have undergone semen cryopreservation in the Regional Reference Center-Seminal Fluid Cryopreservation- Andrology Laboratory of the Careggi University Hospital of Florence}

The presence of the SARS-CoV-2 viral genome was investigated by RT-PCR in the seminal matrices of 111 subjects who performed the collection of semen for cryopreservation in our Lab in the period May 2020-January 2021 independently of the NPS results. Figure 2 shows the pie chart representing the percentage of oncological (81/111 subjects, $73.0 \%)$ and non-oncological subjects (30/111 subjects, 27.0\%), (panel A), who underwent both a NPS (panel B) and a search for the viral RNA in the seminal matrix (panel C). Only two subjects tested positive for NPS (1.8\%, panel B), but in neither of them the viral RNA was detected in the matrix (panel C).

\section{Discussion}

Due to its rapid global spread, high transmissibility and high frequency of complications, since the end of 2019 , the world has been fighting to keep the SARS-CoV-2 pandemic under control. Infection occurs primarily through respiratory droplets, however, other routes of transmission cannot be excluded, increasing the possibility of the impact of SARS-CoV-2 on multiple organs. It has been hypothesized that the male reproductive system is a potential target for SARS-CoV-2 infection [4]. In this scenario, there are rising concerns on how SARS-CoV-2 infection could affect male fertility as well as possibilities of seminal contamination and transmission.

In many countries, following recommendations of some international scientific societies, whenever possible, fertility treatments were postponed, however, semen cryopreservation, in case of oncological patients undergoing gonadotoxic therapies, could not be brought to a standstill. Therefore, there was an urgent need to understand which are the risks associated with the collection and the processing of human male gametes during COVID-19 pandemic, and, in particular, the hazards related to the banking of these samples, which theoretically could be infected with SARS-CoV-2.

Especially at the beginning, very little knowledge was available about this new virus, hence, public and private laboratories tried to activate measures and protocols to ensure the safety of both samples they managed and stored, and the staff who handled them. However, the management of 


\section{A}

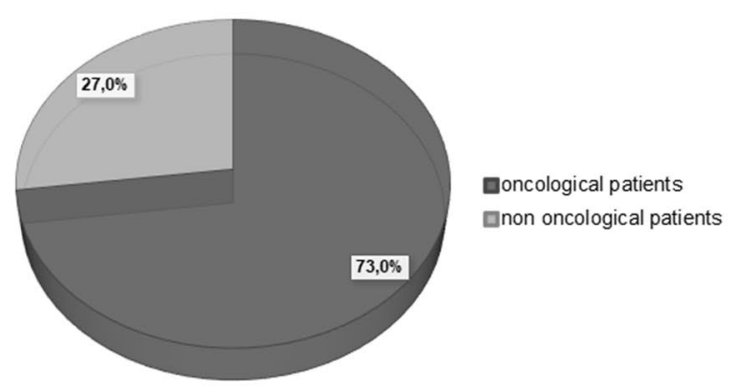

B

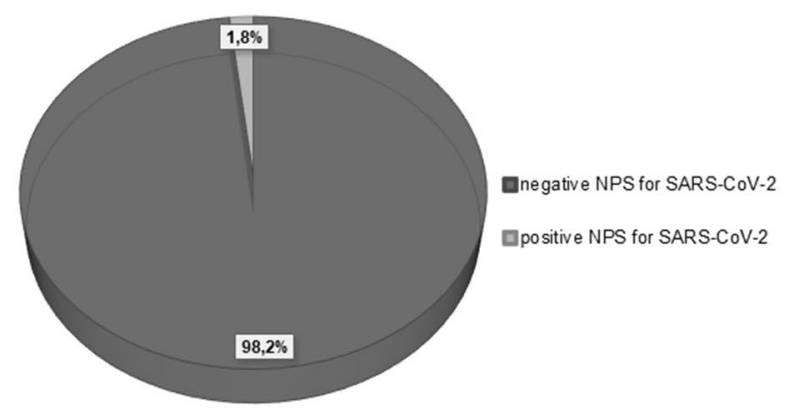

C

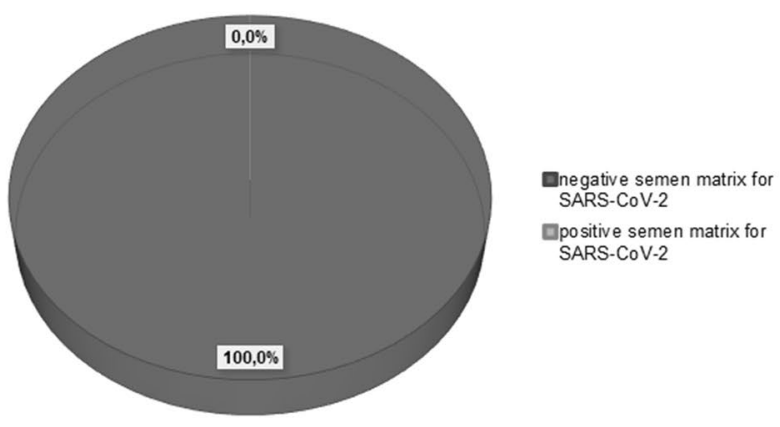

Fig. 2 Pie charts showing the percentages of oncological and nononcological patients (panel A), the percentages of patients resulted positive or negative to NPS (panel B) and the percentages of patients resulted positive or negative to search of SARS-CoV-2 mRNA

sperm cells raised several concerns on what were the correct measures to adopt.

To our knowledge, this is the first survey investigating the preventive measures and procedures applied during COVID19 pandemic on semen cryopreservation. To have the most possible complete picture both at national and European level, we asked two important andrology societies to stimulate semen cryopreservation centers to fulfill the survey.

As reported in the results, no particularly drastic measures were taken by the majority of centers to prevent the risk of contamination or transmission of SARS-CoV-2 infection. Indeed, the most common strategy adopted by the centers (77.3\%) was the administration of a questionnaire to men before cryopreservation to evaluate possible contacts with infected people or the presence of symptoms attributable to COVID-19. Whether this strategy can be sufficient to exclude infection is questionable, as asymptomatic subjects have been described [21]. Most of the centers do not request NPS before cryopreservation (from 24 to $72 \mathrm{~h}$ before sample collection and freezing). Moreover, in case of the absence of NPS response on time, only few centers use a quarantine tank. Of note, in the event of a NPS positive patient, only $4 / 22$ laboratories store the sample in a dedicated tank. The use of separate tanks for subjects with serum virus positivity is indicated in the last two editions of WHO manual [22, in seminal matrix (panel $\mathbf{C}$ ) related to 111 men attending to the Regional Reference Center-Seminal Fluid CryopreservationAndrology Laboratory of the Careggi University Hospital of Florence for semen cryopreservation

23], but different countries have different rules regarding this point. Italian legislation for gamete cryopreservation has established that it is necessary to have dedicated cryogenic containers for each of the different screened pathologies [24]. However, until now, no cross-contamination among cryopreserved semen samples were recorded also thank to the employment of highly secure devices and segregated cryovessels [25].

Although all centers participating to the survey performed semen cryopreservation in case of NPS positive patients that cannot delay because of initiation of lifesaving therapies, it is necessary that semen collection is performed outside of the laboratory (at home or in the hospital in case of hospitalized patients). The bank should foresee an accurate sanitization of all the devices and adopt specific security measures and protocols to ensure the safety of the operators employed in the center as well as of the other samples.

According to data available in literature, the risk of sexual transmission of SARS-CoV-2 from semen due to presence of virus or contamination is low [18], although larger cohort of subjects will be required to have a clear picture on this risk.

The experience of the Regional Reference Center-Seminal Fluid Cryopreservation-Andrology Laboratory of the Careggi University Hospital of Florence, being the only center among those participating to the survey that searched 
for SARS-CoV-2 RNA in the seminal matrix, strengthened such a fact. Indeed, the viral genome was not detected in the semen of any of the 111 patients undergoing cryopreservation, including two men who resulted positive to NPS in agreement with the majority of the previous studies [8-14]. In addition, in a recent observational cohort trial, no detectable viral RNA was found in different fluids of reproductive tracts, including semen, of subjects undergoing ART, of which few with a positive NPS [26], confirming that the risk of occurrence of the virus in such fluids is minimal. However, considering that currently there are no validated methods for detection of SARS-CoV-2 RNA in semen, the use of a separate tank in case of semen sample of NPS positive patients could represent a further security measure.

In conclusion, this survey revealed that semen banks operating in Europe use variable measures to handle and manage semen samples for cryopreservation during COVID19 pandemic period. In particular, most centers do not even require an NPS of the patient before the procedure. Although current evidence indicates low risk for sexual transmission of the virus, knowing the results of an NPS is advised in our opinion because it could be important in couple counseling when using the sample in an ART center. In addition, the personnel operating in the bank/ART center is warned of managing possible infected semen. Knowledge about this Coronavirus is still limited but in continuous evolution; therefore, it is advisable to behave with the utmost caution and use safe devices for sample handling and storage.

\section{Declarations}

Conflict of interest On behalf of all the authors, the corresponding author states that there is no conflict of interest. L. Vignozzi is a member of the Editorial Board of the journal.

Ethical approval The data reported in this study derive from a questionnaire administered to European semen banks. The questions in the survey do not concern human biological samples but only the cryopreservation procedures adopted during COVID-19 pandemic. For these reasons, the ethics approval is not required. However, semen cryopreservation procedures performed in all centers were in accordance with the ethical standards of the institutional and/or national research committee and with the 1964 Helsinki Declaration and its later amendments or comparable ethical standards.

Informed consent Informed consent was obtained from all individual patients undergoing semen cryopreservation.

\section{References}

1. Wiersinga WJ, Rhodes A, Cheng AC, Peacock SJ, Prescott HC (2020) Pathophysiology, transmission, diagnosis, and treatment of Coronavirus Disease 2019 (COVID-19): a review. JAMA 324:782-793. https://doi.org/10.1001/jama.2020.12839
2. Wang W, Xu Y, Gao R, Lu R, Han K, Wu G, Tan W (2020) Detection of SARS-CoV-2 in different types of clinical specimens. JAMA 323:1843-1844. https://doi.org/10.1001/jama. 2020.3786

3. Guan WJ, Ni ZY, Hu Y, Liang WH, Ou CQ, He JX, Liu L, Shan H, Lei CL, Hui DSC, Du B, Li LJ, Zeng G, Yuen KY, Chen RC, Tang CL, Wang T, Chen PY, Xiang J, Li SY, Wang JL, Liang ZJ, Peng YX, Wei L, Liu Y, Hu YH, Peng P, Wang JM, Liu JY, Chen Z, Li G, Zheng ZJ, Qiu SQ, Luo J, Ye CJ, Zhu SY, Zhong NS, China Medical Treatment Expert Group for Covid-19 (2020) Clinical characteristics of Coronavirus Disease 2019 in China. N Engl J Med 382:1708-1720. https://doi.org/10.1056/NEJMoa2002 032

4. Wang MY, Zhao R, Gao LJ, Gao XF, Wang DP, Cao JM (2020) SARS-CoV-2: structure, biology, and structure-based therapeutics development. Front Cell Infect Microbiol 10:587269. https://doi. org/10.3389/fcimb.2020.587269

5. Singh M, Bansal V, Feschotte C (2020) A single-cell RNA expression map of human coronavirus entry factors. bioRxiv. https://doi. org/10.1101/2020.05.08.084806

6. Salam AP, Horby PW (2017) The breadth of viruses in human semen. Emerg Infect Dis 23:1922-1924. https://doi.org/10.3201/ eid2311.171049

7. Rastrelli G, Di Stasi V, Inglese F, Beccaria M, Garuti M, Di Costanzo D, Spreafico F, Greco GF, Cervi G, Pecoriello A, Magini A, Todisco T, Cipriani S, Maseroli E, Corona G, Salonia A, Lenzi A, Maggi M, De Donno G, Vignozzi L (2021) Low testosterone levels predict clinical adverse outcomes in SARS-CoV-2 pneumonia patients. Andrology 9:88-98. https://doi.org/10.1111/andr.12821

8. Ma L, Xie W, Li D, Shi L, Ye G, Mao Y, Xiong Y, Sun H, Zheng F, Chen Z, Qin J, Lyu J, Zhang Y, Zhang M (2021) Evaluation of sex-related hormones and semen characteristics in reproductiveaged male COVID-19 patients. J Med Virol 93:456-462. https:// doi.org/10.1002/jmv.26259

9. Guo L, Zhao S, Li W, Wang Y, Li L, Jiang S, Ren W, Yuan Q, Zhang F, Kong F, Lei J, Yuan M (2021) Absence of SARS-CoV-2 in semen of a COVID-19 patient cohort. Andrology 9:42-47. https://doi.org/10.1111/andr.12848

10. Pan F, Xiao X, Guo J, Song Y, Li H, Patel DP, Spivak AM, Alukal JP, Zhang X, Xiong C, Li PS, Hotaling JM (2020) No evidence of severe acute respiratory syndrome-coronavirus 2 in semen of males recovering from coronavirus disease 2019. Fertil Steril 113:1135-1139. https://doi.org/10.1016/j.fertnstert.2020.04.024

11. Song C, Wang Y, Li W, Hu B, Chen G, Xia P, Wang W, Li C, Diao F, Hu Z, Yang X, Yao B, Liu Y (2020) Absence of 2019 novel coronavirus in semen and testes of COVID-19 patients. Biol Reprod 103:4-6. https://doi.org/10.1093/biolre/ioaa050

12. Holtmann N, Edimiris P, Andree M, Doehmen C, Baston-Buest D, Adams O, Kruessel JS, Bielfeld AP (2020) Assessment of SARSCoV-2 in human semen-a cohort study. Fertil Steril 114:233-238. https://doi.org/10.1016/j.fertnstert.2020.05.028

13. Paoli D, Pallotti F, Colangelo S, Basilico F, Mazzuti L, Turriziani O, Antonelli G, Lenzi A, Lombardo F (2020) Study of SARS$\mathrm{CoV}-2$ in semen and urine samples of a volunteer with positive naso-pharyngeal swab. J Endocrinol Invest 43:1819-1822. https:// doi.org/10.1007/s40618-020-01261-1

14. Khalili MA, Leisegang K, Majzoub A, Finelli R, Panner Selvam MK, Henkel R, Mojgan M, Agarwal A (2020) Male fertility and the COVID-19 pandemic: systematic review of the literature. World J Mens Health 38:506-520. https://doi.org/10.5534/wjmh. 200134

15. Li D, Jin M, Bao P, Zhao W, Zhang S (2020) Clinical characteristics and results of semen tests among men with Coronavirus Disease 2019. JAMA Netw Open 3:e208292. https://doi.org/10. 1001/jamanetworkopen.2020.8292 (Erratum in: JAMA Netw Open 2020 3:e2010845) 
16. Saylam B, Uguz M, Yarpuzlu M, Efesoy O, Akbay E, Çayan S (2021) The presence of SARS-CoV-2 virus in semen samples of patients with COVID-19 pneumonia. Andrologia 53:e14145. https://doi.org/10.1111/and.14145

17. Gacci M, Coppi M, Baldi E, Sebastianelli A, Zaccaro C, Morselli S, Pecoraro A, Manera A, Nicoletti R, Liaci A, Bisegna C, Gemma L, Giancane S, Pollini S, Antonelli A, Lagi F, Marchiani S, Dabizzi S, Degl'Innocenti S, Annunziato F, Maggi M, Vignozzi L, Bartoloni A, Rossolini GM, Serni S (2021) Semen impairment and occurrence of SARS-CoV-2 virus in semen after recovery from COVID-19. Hum Reprod 36:1520-1529. https://doi.org/10. 1093/humrep/deab026

18. Sengupta P, Leisegang K, Agarwal A (2021) The impact of COVID-19 on the male reproductive tract and fertility: a systematic review. Arab J Urol 19:423-436. https://doi.org/10.1080/ 2090598X.2021.1955554

19. Paoli D, Pallotti F, Nigro G, Aureli A, Perlorca A, Mazzuti L, Di Carlo D, Turriziani O, Lenzi A, Lombardo F (2021) Sperm cryopreservation during the SARS-CoV-2 pandemic. J Endocrinol Invest 44:1091-1096. https://doi.org/10.1007/ s40618-020-01438-8

20. Veiga A, Gianaroli L, Ory S, Horton M, Feinberg E, Penzias A (2020) Assisted reproduction and COVID-19: a joint statement of ASRM, ESHRE and IFFS. Hum Reprod Open 2020:hoaa033. https://doi.org/10.1093/hropen/hoaa033

21. Gao Z, Xu Y, Sun C, Wang X, Guo Y, Qiu S, Ma K (2021) A systematic review of asymptomatic infections with COVID-19.
J Microbiol Immunol Infect 54:12-16. https://doi.org/10.1016/j. jmii.2020.05.001

22. World Health Organization (2010) WHO laboratory manual for the examination and processing of human semen, 5th edn. Cambridge University Press, Cambridge

23. World Health Organization (2021) WHO Laboratory Manual for the Examination and Processing of Human Semen, 6th ed. Geneva

24. 28/CSR (21 Febbraio 2019) La conferenza permanente per i rapporti tra lo Stato, le Regioni e le Province Autonome di Trento e Bolzano. https://www.statoregioni.it/it/conferenza-stato-regioni/ sedute-2019/seduta-del-21022019/atti/repertorio-atto-n-28csr/

25. Yakass MB, Woodward B (2020) COVID-19: should we continue to cryopreserve sperm during the pandemic? Reprod Biomed Online 40:905. https://doi.org/10.1016/j.rbmo.2020.04.004

26. Kteily K, Pening D, Vidal PD, Devos M, Dechene J, Op De Beeck A, Botteaux A, Janssens S, Van den Abbeel E, Goldrat O, Delbaere A, Demeestere I (2021) Risk of contamination of semen, vaginal secretions, follicular fluid and ovarian medulla with SARS-CoV-2 in patients undergoing ART. Hum Reprod. https://doi.org/10.1093/humrep/deab255 (Epub ahead of print)

Publisher's Note Springer Nature remains neutral with regard to jurisdictional claims in published maps and institutional affiliations. 